\title{
Hegel e a música de seu tempo
}

\author{
Carl Dahlhaus \\ TRADUÇÃo DE REgINALdo Rodrigues Raposo
}

$\mathbf{I}^{\mathrm{I}}$

A relação [Verbältnis] dos grandes filósofos alemães dos séculos XVIII e XIX com a música - Nietzsche representa a exceção - é estranhamente caracterizada por uma relação [Relation] enviesada entre a experiência musical, a compreensão filosófica e o efeito histórico musical. O fato da experiência musical ter sido escassa - como em Kant e Schelling - ou influenciada por preconceitos - como em Hegel e Schopenhauer - não impediu de maneira alguma que os filósofos, em certa medida compelidos pelo sistema, chegassem a conhecimentos estético musicais, que foram aceitos pelos músicos, embora relutantemente no início, e foram integrados ao pensamento "sobre" a música e muitas vezes mesmo ao pensamento "na” música. A diferenciação de Hermann Kretzschmar entre a "estética dos músicos", que se distingue pela proximidade com o assunto [Sachnähe], e uma "estética dos filósofos", que flutua no ar rarefeito das abstraçôes, é historicamente cega, pois negligencia o fato paradoxal, mas óbvio, de que as consequências histórico musicais as mais palpáveis estão baseadas justamente nas especulações

'DAHLHAUS, C. "Hegel und die Musik seiner Zeit". In: Klassische und romantische Musikästhetik. Laaber: Laaber-Verlag, 1988, pp. 230 a 248; também publicado anteriormente no caderno 22 da revista Hegel-Studien (pp. 333 a 350). Nota da tradução.

${ }^{2}$ KRETZSCHMAR, H. “I. Kants Musikauffassung und ihr Einfluss auf die folgende Zeit”. In: Id. Gesammelte Aufsätze aus den Jabrbuch der Musikbibliothek Peters. Leipzig, I9II (Edição Leipzig, 1973), pp. 242 a 256. 
as mais abstratas. Inicialmente pode ser irritante que o efeito histórico se deva em parte a mal-entendidos, porém, para um historiador, que não se ilude pelas doutrinas acerca da amplitude das casualidades na história, isso é um fenômeno comum, pelo qual ele de modo algum se sente inquieto e desafiado a artifícios interpretativos para conseguir extirpar do mundo a discrepância perturbadora.

Se, portanto, deve ser compreensível o fato de que o tema "Hegel e a música de seu tempo" não é inofensivo à história da cultura, mas sim precário na história das ideias, então um aparente desvio, um excurso sobre a recepção de Kant e Schopenhauer, deve ser o procedimento acessível mais imediato.

Trata-se de um fato histórico, tanto do ponto de vista da recepção quanto da sua influência, o assim chamado formalismo estético musical ter sido justificado através da Critica da faculdade do juizo de Kant, e seria absurdo negá-lo, embora estranhamente ele atravesse a intenção da qual Kant partiu. Nos capítulos que Kant fala sobre música, não é sem sinais de embaraço que ele se mostra um apoiador aberto da doutrina dos afetos. O efeito histórico do livro, assim como o estético musical, originou-se nos parágrafos em que o juízo estético, expresso concisamente, designa o "puramente formal". O fato de a análise kantiana do conceito se tornar a carta de fundação do formalismo estético musical baseia-se no erro, contrariamente à visão de Kant, de, sem mais, se igualar o juízo estético ao juízo artístico. Expresso de outro modo: o juízo artístico, que segundo a conviç̧ão de Kant implicitava traços distintivos [Bestimmungsmerkmale] éticos e práticos, se a arte deve ser não o mero "aprazimento" mas antes "cultura" [Kultur], é reduzido ao juízo estético, que exclui momentos éticos e práticos da compreensão do "belo em si". E o resultado da redução errônea foi o formalismo estéticomusical, que Kant não queria, mas provocou. E o mal-entendido com efeito fez história pelo fato de a teoria do juízo estético ter servido como justificação filosófica de uma ideia que concomitantemente, nos anos de 1790, foi concebida literariamente por Wackenroder e Tieck: a ideia de uma música instrumental autônoma e absoluta, que não necessita ser legitimada nem por funções que ela cumpre, nem por afetos que ela apresenta ou evoca. A música, proclamou Tieck, é "um mundo à parte por si mesmo", 3 e a música, à qual ele se referiu,

3 WACKENRODER, W. H.; TIECK, L. "Die Töne”. In: WACKENRODER, W. H. Dichtung, Schriften, Briefe. Edição de G. Heinrich. Berlin, 1984, p. 345. 
era uma "música instrumental”, que, em contrapartida à estética tradicional da música vocal, foi elevada no romantismo a paradigma do filosofar sobre a música. Que a ideia de música absoluta adveio menos de experiências musicais do que se enraizou em pressupostos literários - ela surgiu através da transferência do "topos do indizível” poético para a música -, não impediu que ela tenha ocasionado um efeito histórico verdadeiramente avassalador; um efeito histórico, a cuja origem pertenceu o prestígio que aumentara para o gênero da sinfonia nos anos de 1790 na consciência dos ilustrados de toda a Europa através dos êxitos de Haydn em Londres.

A configuração das distinções conceituais de Kant, o entusiasmo de Wackenroder e Tieck inspirado por Jean Paul, e o enobrecimento da sinfonia alcançado por Haydn com dura consequência desde o frívolo divertissement a um fenômeno cultural de classificação comparável com a literatura e a pintura, são certamente algo estranho e paradoxal; mas dificilmente se pode negar que deles resultaram as representações sobre música, que se tornaram depois, em interação com a prevalência promovida por Beethoven, a doutrina estético musical dominante de todo o século XIX.

Quando não deixa enganar pela interpretação harmonizadora, a relação entre a intenção e o efeito histórico na filosofia musical de Schopenhauer, sem dúvida a mais influente do século XIX, revela-se de maneira similarmente contraditória. O que Schopenhauer delineou em I819, no primeiro volume de $O$ mundo como vontade e representação ${ }^{4}$ não era nada senão uma metafísica da música instrumental, concebida sob influência de Wackenroder e Tieck. No entanto, pelo fato de Wagner ter se apropriado desde I854 da filosofia de Schopenhauer, esta adentrou um contexto histórico musical, no qual cumpriu uma função, que apesar de ser significante, lhe era insolitamente estranha, e que dificilmente era coerente com o sentido original.

Para Wagner, a recepção de Schopenhauer significou nada menos que uma derrubada, embora não admitida, das convicções estético musicais e dramatúrgicas

${ }^{4}$ SCHOPENHAUER, A. Die Welt als Wille und Vorstellung. v. I. In: Id. Sämtliche Werke. Edição crítica de W. Freiherr von Löhneysen. v. I. Frankfurt am Main, 3a. ed, 1987, \52, pp. 356 a 372 . 
anteriores. Se ele explicara ainda em I851, em Ópera e drama, 5 a música como meio para a finalidade do drama, duas décadas depois, inteiramente no espírito de Schopenhauer, ele dizia, justamente pelo contrário, do drama "tornando-se visivelmente um fato da música”. 6 A música expressa a verdadeira substância de uma ação, para a qual os acontecimentos cênicos e seu suporte linguístico representam um reflexo exterior. Em suma: o drama ilustra a música, e não a música, o drama.

Que Wagner tenha se tornado schopenhaueriano é evidentemente algo que não se explica pela mera influência "a partir de fora", mas sim está ligado - sem mencionar as implicações políticas que estão misturadas com as estéticas - às experiências referentes à relação entre a música e o drama, que se impuseram a Wagner durante a composição de Tristão e Isolda: experiências que contrariaram a sua teoria anterior proclamada em Ópera e drama. No entanto, como consequência histórico musical da recepção wagneriana de Schopenhauer, segue-se o estranho fato, de que ao final do século XIX justamente os gêneros musicais confundidos com a literatura - o drama musical e o poema sinfônico, que constituíram o terreno vocal e instrumental ligados ao "partido progressista musical" vinculado a Wagner e Liszt - foram concebidos e também recebidos esteticamente sob as premissas de uma filosofia, que originalmente, como foi dito, era uma metafísica da música instrumental autônoma e absoluta. E a interpretação estética não foi de maneira alguma, como poderia crer um detrator da filosofia, um apêndice ideológico contrário à verdadeira realidade musical que se manifesta nas obras, mas antes pelo contrário formou uma máxima profundamente influente na práxis composicional e no pensamento "na" música, de modo que um teórico musical deve levá-la em conta da mesma maneira que o deve fazer com o que "reside nas notas" ["in den Noten stebt"]. Ela implica, por exemplo, que Richard Strauss, ${ }^{7}$ embora escrevesse música programática, insistia na afirmação de que a forma musical fundamentalmente seria e deveria ser autônoma: uma afirmação no espírito de

s WAGNER, R. Oper und Drama. Edição comentada de K. Kropfinger. Stuttgart, 1984, p. 19.

${ }^{6}$ WAGNER, R. “Über die Benennung 'Musikdrama”. In: Id. Gesammelte Schriften und Dichtungen. Leipzig, 4a. ed., 1907, v. 9, pp. 302 a 308; aqui, p. 306.

7 Cp.: STRAUSS, R. “Aus meinen Jungend- und Lehrjahren”. In: Id. Betrachtungen und Erinnerungen. Edição de Willi Schuh. Zürich und Freiburg i. Br., 1949, pp. I68 e seguinte. 
Schopenhauer, pois, enquanto a música expressa a "essência" das coisas [Dinge], e o programa, apenas seu "fenômeno" [Erscheinung], é inevitável que a música enquanto estrutura tenha de ser fundamentada e consistente em si mesma. E Gustav Mahler, igualmente como um schopenhaueriano em seu respeito piedoso à memória de Wagner [aus Pietät gegenüber Wagner], pôde primeiro manter e mais tarde revogar o conteúdo programático de suas primeiras sinfonias, sem que por isso tenha mexido na substância da obra, pois o programa representava para ele um mero "aspecto exterior" da música, não importando em última instância metafísica qual a função psicológica que [o programa] cumpre na concepção ou recepção da música: mesmo que tenha sido possível, tanto o compositor quanto o ouvinte, utilizar um programa como veículo da imaginação musical, devia-se estar ciente de que a finalidade da contemplação estética consistia em nada além de desembaraçar-se das escoras auxiliares [Hilfskonstruktionen] para se avançar na compreensão da música; uma música, na qual a essência do mundo assumia a forma sonora, segundo Schopenhauer.

\section{2}

O excurso sobre os caminhos tortuosos, sobre os quais as filosofias de Kant e de Schopenhauer intervêm na história da música, foi necessário para tornar patente e plausível que, se graves simplificaçóes devem ser evitadas, deve-se discernir mais precisamente entre a experiência musical subjacente a uma estética, as intenções filosóficas a ela subsequentes e os efeitos histórico musicais que dela emanam, como habitualmente ocorre.

Portanto, se o tema "Hegel e a música de seu tempo" não é simplesmente um motivo para se pintar um quadro de gênero histórico cultural, mas além disso reivindica um interesse na história das ideias, então seu fundamento reside na expectativa de uma análise suficientemente diferenciada prometer explicações acerca da relação precária entre a experiência musical, a motivação filosófica e o efeito histórico, que se desviam de modo característico e significativo dos pontos de vista obtidos a partir da recepção de Kant e Schopenhauer. Portanto, para se resgatar a hipótese, poder-se-ia mostrar que a relação de Hegel com os acontecimentos musicais essenciais dos anos de I820 em Berlim - o "frenesi por Rossini” [Rossini-Taumel], a recepção de Beethoven, a première de $O$ franco-atirador e a 
redescoberta da Paixão segundo são Mateus - está tão intimamente entrelaçada com as motivações filosóficas da estética musical hegeliana, que o efeito histórico da influência no pensamento "sobre" e no pensamento "na" música teve sua origem diretamente na relação ainda que paradoxal entre experiência e especulação. (Não deve ter surpreendido o fato da redescoberta da Paixão segundo são Mateus ter sido subsumida ao conceito de "música dos anos de I820" - verdadeiramente a primeira descoberta de uma obra, que cem anos antes permaneceu sem ressonância. Uma época dificilmente fica em menor medida marcada pelo que recebe do que pelas obras que ela produz. Para exemplificarmos na atualidade: para os anos de 1960 e 1970, a renaissance de Mahler, que coincidiu com a tendência do estilo juvenil, não foi menos característica do que as tendências composicionais, que sob a influência de John Cage dominaram a música posterior; e só depois, se se relacionar ambos os fenômenos entre si, a afinidade com Mahler e as modernas técnicas de montagem e colagem assim como a "nova tonalidade", que na verdade é uma "nova expressividade", e se se puder entendê-los como dois lados de uma mesma questão, talvez seja possível decifrar a assinatura histórico musical do presente).

\section{3}

Nada seria mais falso do que assumir que Hegel não percebeu eventos significativos que estavam ao alcance. Que ele não tenha mencionado um nome, como o de Hölderlin - pode-se também dizer: evitou mencionar - não quer dizer de maneira alguma, que ele ignorou a questão, pela qual o nome respondia. Em todo caso, os acontecimentos ou as obras, a respeito das quais ele silencia ou parece silenciar, não são menos características e instrutivas no que se refere aos motivos, do que os eventos a que ele se refere, ou os documentos que ele cita.

Portanto, o silêncio de Hegel sobre Beethoven - que mesmo tendo sido constatado pelos exegetas, não foi, entretanto, interpretado - é sem exagero um silêncio eloquente pedindo para ser decifrado. Se o historiador da música vienense Raphael Kiesewetter, na busca por resumir em uma fórmula a assinatura musical do primeiro momento da restauração, falava de uma "era de Beethoven e Ros- 
sini”, ${ }^{8}$ então Hegel face à dicotomia, que não era nada menos que uma oposição entre duas concepçóes a respeito do que a música em geral seria, encerraria ou expressaria, tomou inequivocamente partido de Rossini e foi contra Beethoven. A acusação de vazio interior levantada contra Rossini feita pelos puristas estéticos, que deram o tom em Berlim, foi resolutamente rechaçada por Hegel, cuja honestidade intelectual não permitiu uma negação das [suas] simpatias musicais.

Os opositores vociferam nomeadamente contra a música de Rossini como se se tratasse de cócegas auditivas; mas quando se se detém mais atentamente em suas melodias [lebt man sich aber näher in ibre Melodie hinein], então, pelo contrário, essa música se torna sumamente plena de sentimentos, espirituosa e penetrante para o coração e o ânimo, mesmo que ela não se enquadre no tipo característico que particularmente agrada o severo entendimento musical alemão. ${ }^{9}$

O "frenesi por Rossini”, que na época foi sentido em toda Europa, também não deixou, portanto, Hegel incólume, que aproveitou uma estadia em Viena acima de tudo para desfrutar das óperas de Rossini; e não falta ironia ao se ler uma invectiva contra o severo entendimento musical alemão em uma estética que emergiu de uma Fenomenologia do espirito.

Beethoven, pelo contrário, como foi dito, não é em lugar algum o assunto, e a conjetura consiste em que o silêncio conspícuo surgiu de um sentimento ambíguo, um sentimento desconcertantemente misto de desconfiança face à orientação da música instrumental perseguida por Beethoven e da timidez em polemizar indisfarçadamente contra um fenômeno musical de inquestionável alcance. A hipótese, que antes de tudo parece ser consequência do veredito de Gottfried Benn (de que a psicologia seria uma mera insolência), consolida-se na probabilidade filologicamente fundada, na medida em que se nota que a teoria de Hegel da música instrumental compreende uma réplica velada da apologia de Beethoven feita por E.T.A Hoffmann, que em I8Io aparecia no Jornal musical

${ }^{8}$ KIESEWETTER, R. G. Geschichte der europäisch-abendländischen oder unsrer heutigen Musik. Leipzig, 2a. ed, I846 (edição Niederwalluf, 1972), pp. 98 a Ioo.

9 HEGEL, G. F. W. Ästhetik. Edição de F. Bassenge. Berlin e Weimar, 3ª ed., I976, v. 2, p. 327. 
geral [in der Allgemeinen Musikalischen Zeitung] ${ }^{\text {Io }}$ e cuja parte essencial foi mais tarde incorporada por Hoffmann no primeiro volume das Phantasiestücke [Fantasiestücke in Callots Manier], de maneira que dificilmente se pode supor que Hegel, leitor insaciável, não tenha conhecido o escrito de Hoffmann. Afinal, em Berlim, mesmo quando se mantinha internamente distância, vivia-se em imediata proximidade um do outro.

A passagem da Estética que resume ao máximo a opinião de Hegel sobre a música instrumental parte da diferença entre a linguagem, que utiliza o som como mero meio para a finalidade da compreensão conceitual, e a música, na qual os sons tendem a servir não como signos, mas sim para reivindicar uma existência autônoma e significado.

Se olharmos para a diferença do emprego poético e musical do som, veremos que a música não oprime o som em som verbal, e sim faz do som mesmo por si seu elemento, de modo que ele, na medida em que é som, é tratado como finalidade. Desse modo, o reino dos sons, já que não deve servir apenas para a mera designação, pode neste "livre tornar-se" [Freiwerden] chegar a ser um modo de configuração que permite à sua própria Forma, como configuração sonora [Tongebilde] ricamente artística, tornar-se sua finalidade essencial. Particularmente em época mais recente, a música, rompendo com um Conteúdo por si mesmo já claro, retornou assim ao seu próprio elemento, mas para isso perdeu também tanto mais poder sobre todo o interior, na medida em que o prazer que ela pode oferecer apenas se volta para um lado da arte, ao mero interesse, a saber, para o que é puramente musical da composição e sua habilidade, um lado

${ }^{10}$ HOFFMANN, Ernst Theodor Amadeus. Rezension über Beeethovens 5. Sinfonie. Aparece pela primeira vez in: Allgemeine Musikalische Zeitung I2 (I809/18Io), pp. 630 a 642, mais tarde 652 a 659 (nova edição in: Schriften zur Musik. Suplemento. Edição de F. Schnapp. Munique, 1963, pp. 34 a 51; parcialmente em Id. Fantasiestücke in Callots Manier (Nr. III/4). In: Id. Fantasie- und Nachstücke. Edição de W. Müller-Seidel. Munique, 1960, pp. 4I a 49. 
que é apenas questão para especialista e importa menos ao interesse artístico universalmente humano. ${ }^{\text {II }}$

Que Hegel, o antirromântico, se reporte secretamente à crítica de Hoffmann à quinta sinfonia de Beethoven nas sentenças citadas é algo extremamente provável na medida em que Hoffmann e Hegel descrevem o mesmo acontecimento significativo do ponto de vista histórico musical, um acontecimento que para consciência dos contemporâneos foi representado antes de tudo pela obra de Beethoven; mesmo assim eles tomam partido em sentido oposto.

O "puramente musical" - que Hegel via como um encolhimento e, portanto, um modo deficiente da música - não é nada além da música instrumental autônoma, a respeito da qual Hoffmann entusiasticamente proclamou que, "desdenhando de qualquer ajuda e qualquer mistura com outra arte, ela expressa de maneira pura a essência peculiar da arte, que somente nela mesma se pode reconhecer". ${ }^{12}$ A "separação de um Conteúdo [Gehalt] por si mesmo já claro", a qual Hegel lamentou, foi exaltada por Hoffmann como emancipação e como conversão da música em uma cifra do "indizível”: a música, que graças à sua carência de "determinidade" foi sentida no século XVIII como subalterna à linguagem verbal, foi pelo mesmo motivo mais tarde elevada acima da linguagem verbal - através da inversão não das premissas, mas das consequências. "A música abre para os seres humanos um reino desconhecido; um mundo, que não tem nada em comum com o mundo sensível exterior que o circunda, e que nele deixa para trás todos os sentimentos determináveis por conceitos, para se dedicar ao "inexprimível” [Unaussprechlichen]". ${ }^{13}$ A "ausência de conceito" [Begriffslosigkeit] da música, que na época do esclarecimento incitou a suspeita de que ela não seria nada além de um ruído vazio, foi por Hoffmann reinterpretada como uma expressão de "pressentimentos" [Ahnungen], em que, ainda que vagamente, se faz audível um fragmento de metafísica. E finalmente a perda do "interesse artístico

II Trecho traduzido retirado de HEGEL, G. W. F. Cursos de estética, Tradução de Marco Aurélio Werle e Oliver Tolle. São Paulo, Edusp, 20I4, v. III, p. 286 e 287. Nota da tradução. (Asthetik, 1976, v. 2, p. 317).

${ }^{12}$ HOFFMANN, E.T.A. "Rezension über Beeethovens 5. Sinfonie”. In: Schriften zur Musik. Suplemento. Edição de F. Schnapp. Munique, 1963, pp. 34 a 51, aqui, p. 34.

${ }^{13} \mathrm{Id}$. 
universalmente humano", que Hegel diagnosticou, - uma perda que veio à luz no século XX como divisão do público entre conhecedores e desinteressados - foi reconhecida por Hoffmann como um preço inevitável que a música deve pagar para que ela expresse de maneira pura sua "essência peculiar". Se ele diz ainda de Haydn, que ele "seria mais comensurável para a maioria" "i4 do que Mozart ou ainda mais Beethoven, então a música de Beethoven, como Hoffmann quis dizer, somente se abre através de um "exame bastante aprofundado da estrutura interior". ${ }^{\text {I5 }}$

As tendências que Hegel enxergou como perigos [als Gefabren]: o retorno da música ao "seu elemento próprio", a "separação" de um "sentimento determinado por conceitos" e a apelação para o juízo do "especialista" ao invés do sentimento [Empfindung] do "amador" - para expressar na linguagem do século XVIII -, são em suma as mesmas [tendências], em que Hoffmann reconheceu os sinais do tempo; um tempo, entretanto, com o qual ele se sentiu, ao contrário de Hegel, em concordância. E, que isso seja a estética musical romântica, a cuja metafísica da música instrumental Hegel se reportou dissimulada e polemicamente, é algo que pode surpreender, uma vez que aponta para o fato da dialética da emancipação e estranhamento [Entfremdung], autonomia e perda da substância, - que, poderse-ia dizer, surgiria somente na Nova Música do século XX - haver sido concebida, já na época do romantismo, como problema central de uma estética musical fundada histórico-filosoficamente.

Contudo, o contexto filosófico, a partir do qual a dialética da música instrumental autônoma de Hegel deve ser compreendida, apesar de ter sido ignorado pelos exegetas, claramente não consiste em nada diferente da tese conhecida e constantemente citada do fim da arte - ou mais precisamente: da perda de substância da arte.

Repetir ainda uma vez o que a tese diz e o que ela não diz seria um pedantismo desnecessário. Será suficiente lembrar-se das implicações: que a perda na substância religiosa não exclui de modo algum um ganho no virtuosismo artificial, mas justamente constitui seu lado inverso. "Para nós a arte não vale mais como o modo mais alto segundo o qual a verdade proporciona existência para si (...)

\footnotetext{
${ }^{14}$ Ibid., p. 36.

is Ibid., p. 37.
} 
Podemos bem ter esperança de que a arte vá sempre progredir mais e se consumar, mas sua Forma deixou de ser a mais alta necessidade do espírito". ${ }^{16}$

O evento histórico, que Hegel apostrofou como "fim da arte", é o mesmo que os estetas e historiadores da arte, via de regra, caracterizam como a passagem da funcionalidade para a autonomia, como a "liberação" da arte para si mesma, para a existência e a significação autônomas. ${ }^{17} \mathrm{E}$, se Hegel, na sentença que fala da perda de substância da arte, de maneira nenhuma exclui, por outro lado, a possibilidade de que “a arte vá sempre progredir mais e se consumar”, então a formulação ambígua e dialética não significa outra coisa senão que a autonomia da arte seria um progresso da artificialidade (formal), que deveria ser pago através de um prejuízo de Conteúdo (religioso). A unidade da substância e da forma artística, que Hegel viu realizada na antiga "religião da arte" - na presença corpórea do deus na estátua do deus - foi desintegrada. E com um exagero pontual, mas não em contradição com Hegel, poder-se-ia afirmar que a tese do fim da arte diz que o fim da arte enquanto religião aponta para o início da arte enquanto arte. De qualquer modo, no pensamento de Hegel o sentido metafísico e o caráter estético-técnico da arte - ou seja, o que sob as premissas dos tempos modernos faz da arte, arte - surgem em oposição um ao outro.

A correlação entre a experiência musical e a motivação filosófica, cuja reconstrução de início foi designada como o propósito da investigação, deveria, portanto, ser evidenciada. O silêncio a respeito de Beethoven - que pode expressar o fato da teoria da música instrumental autônoma de Hegel poder ser decifrada como uma polêmica enrustida contra a apologia de Beethoven feita por E.T.A. Hoffmann - revela, no entanto, acima de tudo, que Hegel enxergava na música absoluta (que se arranca de um conteúdo sentimental determinado por conceitos, e por isso mesmo reivindica, como forma pura ou estrutura, a dignidade metafísica enquanto linguagem além e acima do nível verbal) um caminho errático por onde o "interesse artístico universalmente humano" teve de se exaurir. Não que ele tivesse ignorado a grandeza de Beethoven, sobre a qual nos anos de 1820 quase

${ }^{16}$ Trecho traduzido retirado de HEGEL, G. W. F. Cursos de estética, Tradução de Marco Aurélio Werle e Oliver Tolle. São Paulo, Edusp, 20oI, v. I, p. I77. Nota da tradução. (Ästhetik, 1976, v. 2, p. IIO).

${ }^{17}$ [zu selbständiger Existenz und Bedeutung]. Nota da tradução. 
já não mais havia controvérsia; mas ele diagnosticou nela, em estranha analogia com a crítica de Schoenberg a alguns conservadores no século XX, uma grandeza que conduzia à fatalidade.

A dialética - da música que através de seu próprio progresso, pelo qual ela chega "a si mesma", perde em substância, - foi portanto no contexto da estética ou filosofia histórica da arte hegeliana uma versão específica (submetida a uma subárea) da tese do fim da arte, uma tese que igualmente, como foi dito, como o outro lado de uma perda de Conteúdo religioso, constatou ou previu ou ao menos não excluiu um acréscimo de artificialidade [Artifizialität].

A resposta a Hegel formulada em I854 por Eduard Hanslick, ${ }^{18}$ de que a forma musical enquanto tal seria "espírito" - uma sentença, que apresenta a fórmula mais concisa para o evento histórico-musical que se deu com a música instrumental de Beethoven - foi justamente o que Hegel negou e teve de negar diante das premissas de seu sistema. Hegel provavelmente compreendeu inteiramente o que ocorria do ponto de vista histórico-musical e o que se manifestava nas sinfonias de Beethoven, mas se debateu contra isso.

\section{4}

Em decorrência disso, se Hegel acreditou reconhecer na música absoluta, que se arranca de um conteúdo determinável por conceitos ou de uma expressão afetiva, um caminho errático, no qual um ganho na diferenciação formal deveria ser pago com uma perda no "interesse artístico universalmente humano", da mesma forma ele viu no extremo mais oposto como isso igualmente o confrontou nos anos de I820: na sujeição sem reservas da música aos propósitos do caráter [Charakteristik] cênico ou textual, justamente uma ameaça para a essência da música: um abuso, que ele confrontou com franca polêmica. $\mathrm{O}$ objeto que incitou a censura de Hegel foi espantosamente $O$ franco-atirador de Weber, cuja première em Berlim de junho de I82I fora um triunfo, que ainda naquele ano ou no próximo se propagou por quase todos os palcos alemães. É improvável que o juízo duro de Hegel tenha sido determinado por um partidarismo a favor

${ }^{18}$ HANSLICK, E. Vom Musikalisch-Schönen. Leipzig, I854 (Edição Darmstadt, 1865, pp. 87 a 92). 
dos apoiadores de Spontini e contra os de Weber, apesar de não se poder fazer então uma representação unilateral ou fraca demais da influência do partido de Spontini berlinenese, não somente nos círculos da nobreza, mas também entre os burgueses. ( $\mathrm{Na}$ fórmula simples, de que a uma ópera de orientação franco-italiana feita para a nobreza se opunha uma ópera nacional burguesa, a controvérsia não pode de maneira alguma ser compreendida). O veredito de Hegel, em vez de ser um mero ponto de vista partidário, lembra mais a perplexa indignação de Franz Grillparzer ${ }^{19}$ diante da música de Weber, que ele censurou por dilacerar e despedaçar a melodia no que se refere ao caráter, e, portanto, por destruir ou fazer retroceder o vínculo progressivo, a conexão melódica por longos percursos, em nome de efeitos momentâneos. Até mesmo Wagner, que se sentia como que o herdeiro da ópera romântica alemã e declarou entusiasticamente ser Weber o seu modelo, dizia em i851, em Ópera e drama, do "estranho mosaico melódico" [seltsamer Mosaikmelodik]. ${ }^{20}$

O contexto filosófico, a partir do qual a crítica hegeliana de Weber deve ser entendida, deu origem à disputa acerca do característico [Charakteristische] na arte, que nos anos de 1790 era conduzida tanto nos círculos dos classicistas de Weimar bem como nos do romantismo de Jena, mesmo que sob premissas diferentes e com resultados divergentes. Basta lembrar do diálogo de Goethe "O colecionador e sua família" (1798/99), ${ }^{21}$ do artigo de Humboldt "Sobre a forma masculina e feminina" $(1795)^{22}$ e do tratado de Friedrich Schlegel "Sobre o estudo da poesia grega" (I797). ${ }^{23}$ Sem que se tivesse de prosseguir até as minúcias e ramificações da discussão, na qual se manifestou um sentimento preciso (marcando particularmente os anos de 1790) por sutilezas da teoria estética, pode-se supor, em um

\footnotetext{
${ }^{19}$ GRILLPARZER, F. Werke. Edição de S. Hock. Berlin, s/ ano, v. I2, p. Io4.

${ }^{20}$ Cp. WAGNER, R. Oper und Drama. Edição comentada de K. Kropfinger. Stuttgart, I984, pp. 87 a 92.

${ }^{21}$ Cp. GOETHE, J. W. "Der Sammler und die Seinigen”, 6a carta. In: Goethes Werke. Edição de E. Trunz (edição hamburguesa), v. I2. Munique, I98I (nona edição), pp. 79 a 88.

${ }^{22}$ Cp. HUMBOLDT. W. "Über die männliche und weibliche Form”. In: Id. Schriften zur Anthropologie und Geschichte (Werke, edição de A. Flitner e K. Giel, v. I). Stuttgart, 3ª ed., 1980, pp. 296 a 336.

${ }^{23}$ Cp. SCHLEGEL, F. “Über das Studium der griechischen Poesie”. In: Id. Schriften zur Literatur. Edição de W. Rasch. Munique, 1972, pp. 84 a 192.
} 
excurso da história das ideias que tenha Hegel como alvo, que uma controvérsia se inflamou primeiro a partir do problema, se o característico seria admissível somente como um momento dependente e subordinado do belo ou se a arte estaria sujeitada a uma lei de desenvolvimento [Entwiklungsgesetz] que compeliria o belo a progredir para o característico ou a dependência para a autonomia. Pode-se, quando não se despreza as fórmulas reunidas da história das ideias, chamar uma concepção de classicista-normativa e a outra, de romântico-histórico-filosófica.

Por conseguinte, a crítica de $O$ franco-atirador é sinal e expressão de um sentimento fundamental classicista, que Hegel partilhava com Goethe e Humboldt. A autonomização do característico aparece como unilateralidade - em linguagem hegeliana: como "abstração" -, da qual resulta um endurecimento da música, um estranhamento de sua própria essência.

Igualmente importante é, além disso, a relação na qual devem aqui surgir, por um lado, o característico, por outro lado, o melódico. A exigência principal parece-me ser nesta relação a seguinte: a vitória sempre há de ser atribuída ao melódico, enquanto a unidade concentradora, e não à separação em traços característicos singularmente dispersos. Assim, por exemplo, a música dramática atual procura muitas vezes seu efeito em contrastes violentos, na medida em que comprime paixóes opostas, em um e mesmo desenvolvimento musical. (...) Tais contrastes do dilaceramento, que nos lançam sem unidade de um lado para o outro, são tanto mais contra a harmonia da beleza quanto mais unem imediatamente em caracterização aguda coisas opostas, onde então não se pode mais falar do gozo e do retorno do interior para si mesmo na melodia. Em geral, a união do melódico e do característico traz consigo o perigo de facilmente ultrapassar, segundo o lado da descrição mais determinada, os limites suavemente traçados do belo musical (...) Tão logo a música aqui se entrega à abstração da determinidade característica, ela é quase inevitavelmente conduzida para desvios, a penetrar na agudeza, no que é duro, inteiramente não melódico e não musical e mesmo a abusar do desarmônico. ${ }^{24}$

${ }^{24}$ Trecho traduzido retirado de HEGEL, G. W. F. Cursos de estética, Tradução de Marco 
Uma passagem no primeiro volume da Estética, que chama o objeto da aversão pelo nome, mostra que Hegel, com os "contrastes do dilaceramento", que na "música dramática atual” destroem a "unidade concentradora" da melodia, se referia a $O$ franco-atirador de Weber.

Riso e choro podem, contudo, separar-se abstratamente e, nesta abstração, foram também empregados de modo falso como um motivo para a arte, por exemplo, no coro do riso em $O$ franco-atirador de Weber. O riso em geral é um desencadeamento explosivo que, contudo, não deve permanecer incontrolado, caso o ideal não deva ser perdido. ${ }^{25}$

Que Hegel, como parece, não pudera compreender musical e estruturalmente a "explosão incontrolada” do coro zombeteiro - trata-se, falando tecnicamente, de um prolongamento metricamente irregular do acorde de quinta e sexta ${ }^{26}$ do IV grau: de uma argumentação no irritante compasso de oito tempos -, que ele portanto quisera dizer que o coro zombeteiro não seria nada além de um realismo bruto e advindo da estrutura musical, é de um amadorismo musical dificilmente culpável, conforme admitiu Hegel abertamente. No entanto, a experiência musical negativa, que Hegel fazia da música romântica moderna na figura de $O$ franco-atirador nos anos de I820, está por outro lado assaz misturada com motivos filosóficos subjacentes à estética musical hegeliana (nada muito diferente da confrontação com a música absoluta na interpretação de E.T.A. Hoffmann), sem que por ora seja possível desenredar completamente os problemas cronológicos e filológicos associados.

Que o sistema hegeliano da estética apresente conjuntamente uma filosofia da história da arte ou, inversamente, que a filosofia da história da arte apresente conjuntamente um sistema da estética, é um lugar comum da história da filosofia, que no entanto não deveria ter induzido à frase harmonizadora de que o Aurélio Werle e Oliver Tolle. São Paulo, Edusp, 20I4, v. III, p. 332. Nota da tradução. (Ästhetik, 1976, v. 2, p. 316).

${ }^{25}$ Trecho traduzido retirado de HEGEL, G. W. F. Cursos de estética, Tradução de Marco Aurélio Werle. São Paulo, Edusp, 20oI, v. I, p. I7I. Nota da tradução. (Ästhetik, 1976, v. I, p. I6I).

${ }^{26}$ Primeira inversão da tétrade. Nota da tradução. 
sistema e a filosofia da história sempre se coadunam perfeitamente. Como esteta musical, Hegel era antes de tudo um classicista e não um filósofo-historiador [Gechichtsphilosoph], como mostra justamente a crítica a $O$ franco-atirador e sua fundamentação através de um ceticismo primevo face à categoria do característico. Estava ao alcance de Hegel a possibilidade de enxergar no desenvolvimento em direção a um estabelecimento autônomo do característico, e não submetido ao belo, a assinatura estética dos modernos, uma vez que ela havia sido esboçada já por volta de I80o, embora aforisticamente, nas formulações crassas e provocativas de Friedrich Schlegel. E, na estética musical da metade do século, cujas ferramentas a dialética hegeliana forjou, nos textos e declaraçóes jornalísticas de Aldolf Bernhard Marx e Franz Brendel, as tendências do "partido progressista musical” - os esforços de Meyerbeer no drama [Drastik] cênico-musical, a música programática de Franz Liszt, o regionalismo [Lokalkolorit] na ópera romântica e a emancipação do timbre como um parâmetro autônomo da composição musical em Berlioz - foram justificadas e explicadas esteticamente pelo apelo para a categoria do característico ainda reprimida por Hegel.

Contra isso, diferentemente dos hegelianos da época anterior à revolução de março de 1848 , Hegel insistia na tese de que o característico musical só seria admitido esteticamente como um momento parcial não autônomo do belo, que, portanto, em outras palavras, o efeito momentâneo na unidade e continuidade do melódico deveria ser superado [aufgeboben]. Como parece, por alto poder-se-ia afirmar que Hegel, em oposição a seus posteriores adeptos, decidiu-se pelo momento estético normativo-classicista e contra o histórico-filosófico; de uma estética, que no entrecruzamento paradoxal buscava simultaneamente ser a construção de um sistema e representação [Darstellung] da história.

No entanto, não vai longe a simples tese de que a identidade de sistema e história tenha sido mera aparência, que estava constantemente ameaçada de dentro para fora, e que, face às situaçóes concretas como a da tendência moderna para o característico, forçava uma decisão unilateral ou pelo classicismo ou pelo historicismo. Se Hegel, como se mostrou, confrontou a irritante música absoluta com a fórmula dialética de que a música por seu acabamento enquanto arte autônoma padece por outro lado de uma perda na substância espiritual, então não é menos distinta e informativa a interpretação do característico, a qual pode 
ser reconstruída todavia de maneira plausível, mesmo que não se apresente na forma de uma coleção de citaçốes.

O característico musical foi enaltecido por apologetas como Marx e Brendel, que, como foi mencionado, orientaram-se conceitualmente segundo Hegel, como o progredir para a marca [Ausprägung] do espírito na música, como a suplantação do que Marx denominou de "ponto de vista da sensibilidade" ${ }^{27} \mathrm{Hegel}$, em contrapartida, interpretou o processo histórico, sentido por adeptos posteriores como a história do progresso, justa e contrariamente como a história do declínio. "A arte romântica (...); seu interior ela também tece com a contingência da cultura [Bildung] exterior e concede aos traços marcados do não-belo um amplo espaço de jogo" ${ }^{28}$ Por outro lado, para fazer jus à intenção de Hegel não basta o simples esclarecimento de que sob as premissas da filosofia da história, que era concomitante e internamente uma estética classicista-normativa, deveu surgir um período pós-clássico necessariamente como época da decadência; ainda que isso não fosse falso, seria, no entanto, enviesado. Pois o ponto da dialética hegeliana do característico musical reside precisamente no fato de que a elevação do espírito por sobre a esfera das artes, a passagem do primado da arte para a filosofia, na arte, que se mantém apesar da perda de substância, induz a um estado que, de um lado, aparece como declínio pelo recuo do espírito para fora da arte, e, de outro, no entanto, também apresenta-se como um paralelo à marca antes de tudo filosófica do espírito. Se a arte padece de uma diminuição na substância espiritual, por outro lado, ela participa do espírito do tempo [Zeitgeist] representado acima de tudo pela filosofia. Indo além de Hegel, mas no sentido de seu pensamento, podese afirmar que permanece na dupla determinação a essência do característico musical, a qual determinou o desenvolvimento da música no início e na metade do século XIX, um desenvolvimento que se pode interpretar com as categorias de sua filosofia, de acordo com a reivindicação de Hegel de designar as próprias épocas em conceitos. O que os hegelianos proclamaram estético-musicalmente por volta de metade do século XIX era, enquanto pensamento musical no espírito

${ }^{27}$ Cp. MARX, A. B. Die Musik des Ig. Jabrbunderts und ibre Pflege. Leipzig, 3a. ed, I873, pp. 58 a 62 .

${ }_{28}$ Trecho traduzido retirado de HEGEL, G. W. F. Cursos de estética, Tradução de Marco Aurélio Werle. São Paulo, Edusp, 20I4, v. II, p. 26ı. Nota da tradução. (Ästhetik, 1976, v. I, p. 507). 
de Hegel, ao mesmo tempo ilegítimo e legítimo: ilegítimo, pois a unidade da substância espiritual e forma artística, que Hegel viu realizada unicamente nas estátuas de deuses antigas, assim como do característico musical foi imputada à tendência estética dos modernos; porém igualmente legítima, pois também para Hegel entre o caraterístico musical que ele abominava e o espiritual que emigrou da arte para a filosofia permanecia um tipo de afinidade interior, que o conceito do "espírito do tempo" (vocábulo em voga na época anterior à revolução de março de I848) expressa. Se se julga a partir de normas classicistas, pode parecer tratar-se da distorção de um espírito que ganha feições a partir do característico na qualidade de arte de uma época antes de tudo filosófica, mas de todo modo é espírito.

\section{5}

A redescoberta da Paixão segundo são Mateus - a descoberta de que a obra de Bach pode ser admirada não somente enquanto monumento morto, mas reproduzido como obra de arte viva para a práxis musical - foi um evento, que em I829, como lembrou Eduard Devrient (o cantor no papel de Jesus), "causou um furor extraordinário no círculo culto de Berlim”. ${ }^{29}$ Aparentemente também Hegel, assim como Schleiermacher, Droysen e Heine, esteve presente na primeira apresentação em II de março, ou ao menos na reapresentação em 2I de março, pois há o relato de uma anedota maliciosa sobre Hegel no banquete subsequente, a qual Therese Devrient conta em suas memórias. ${ }^{30}$

Que Hegel, como escreveu Zelter para Goethe em 22 de março, deva ter dito: tal "não é música verdadeira; que agora se estaria mais avançado, apesar de se

${ }^{29}$ DEVRIENT, E. Meine Erinnerungen an Felix Mendelssobn Bartholdy und seine Briefe an mich. Leipzig, I869, p. 6I; também in: GECK, M. Die Wiederentdeckung der Matthäuspassion im 19. Jabrbundert. Regensburg, 1967, p. 44

30 Therese Devrient descreve um jantar promovido pelo compositor Carl Friedrich Zelter (1758-1832) após a segunda apresentação da Paixão segundo são Mateus relatada, em que Hegel, sentado ao lado dela (do outro, estava Felix Mendelssohn-Bartholdy, o regente e idealizador do projeto), teria com sua galanteria desajeitada cometido algumas indelicadezas. Cf.: DEVRIENT, Therese. Jungenderinnerungen. Stuttgart: Carl Krabbe Verlag, 1905, pp. 308 e 309. Nota da tradução. 
estar a um longo caminho do que é correto", ${ }^{31}$ é um testemunho, que à primeira vista dá a impressão de ser de todo inverossímil, mas que, como mais tarde será apontado, merece uma interpretação séria.

A passagem na Estética, em que Hegel encomiou entusiasticamente a música sacra de Bach, particularmente "a forma do oratório (...) que primeiro se consumou no protestantismo", ${ }^{32}$ fala em uma língua inteiramente diversa do que a da sentença proferida por Zelter. Apesar disso, há de se considerar que os Cursos de estética foram dados pela última vez no semestre de inverno de I828/29, de maneira que permanece em aberto a possibilidade de que Hegel inicialmente, na Estética, julgara Bach com base em rumores exaltados que circulavam em Berlim, e somente depois pôs em palavras uma experiência musical no sentido do relato de Zelter: uma experiência, cuja decifração filosófica, como foi dito, vale o esforço, apesar de permanecer necessariamente especulativa.

$\mathrm{Na}$ Estética, Hegel dá o mesmo tom com o qual Adolf Bernhard Marx, no Jornal musical geral berlinense [in der Berliner Allgemeinen musikalischen Zeitung], aplainou jornalisticamente o caminho para o feito de Mendelsohn.

Como primeiro tipo principal nós podemos designar a música sacra, a qual, na medida em que ela não tem a ver com a sensação subjetivo-individual, mas sim com o Conteúdo substancial de todas as sensaçôes ou com a sensação geral da comunidade enquanto totalidade, permanece na solidez épica, embora ela não relate nenhum evento enquanto evento (...) sua posição verdadeira, na medida em que ela diz respeito à intercessão sacerdotal em nome da comunidade, ela encontrou no interior do culto católico, enquanto missa, e em geral enquanto elevação nas diferentes formas de açôes e festividades eclesiásticas. Também os protestantes forneceram músicas semelhantes da maior profundidade tanto no sentido religioso quanto

${ }^{3 \mathrm{I}}$ Carta de C. F. Zelter a J. W. von Goethe, 22 (?) de março de I829. In: Briefwechsel zwischen Goethe und Zelter in den Jahren I799-I832. Edição de E. Zehm e S. Schäfer (GOETHE, J. W. Sämtliche Werke nach Epochen seines Schaffens. Edição de K. Richter et al. Edição de Munique, v. 20/2). Munique e Viena, 1998, pp. I208 e seguinte; a citação está na p. I209.

${ }^{32}$ Trecho traduzido retirado de HEGEL, G. W. F. Cursos de estética, Tradução de Marco Aurélio Werle e Oliver Tolle. São Paulo: Edusp, 20I4, v. III, p. 334. Nota da tradução. (Ästhetik, I976, v. 2, p. 318). 
no da solidez musical e riqueza de invenção e execução: como, por exemplo, Sebastian Bach acima de tudo, um mestre, cuja genialidade estupenda, verdadeiramente protestante, vigorosa e mesmo assim erudita [gelehrte] só há pouco tempo se aprende de novo a apreciar integralmente. Entretanto, desenvolve-se aqui primorosamente, à diferença do direcionamento católico, a partir das festas da Paixão, a Forma do oratório consumada primeiro no protestantismo. ${ }^{33}$

Diante do pano de fundo da sistemática filosófica, de onde foi eduzida [ getragen wurde] a estética musical hegeliana, surge, todavia, a distinção, se a Paixão segundo são Mateus representou para Hegel, tal como ele a ouviu (em vez de meramente ler sobre ela), uma marca pura ou turvada do religioso na música turvada por aquilo que Moritz Hauptmann ${ }^{34}$ denominou de "espuma francesa" -, de ser de menor significação do que a interpretação estética histórico-filosófica geral mais ampla, de Palestrina a Bach, que ele buscou dar à toda música sacra, tanto a católica quanto a protestante.

Se a música aparece em geral no sistema de Hegel por princípio e em primeira instância como arte da "interioridade abstrata" e sem objeto: como arte na qual o coração e o ânimo percebem-se a si mesmos nos sons, então Hegel viu na música sacra além disso a possibilidade realizada da "Coisa mesma" [die Sache selbst] e não somente de seu reflexo subjetivo no sentimento do indivíduo "traduzido em sons".

Em músicas sacras antigas, em um Crucifixus, por exemplo, as determinaçóes profundas que residem no conceito da Paixão de Cristo, enquanto este sofrimento, morte e sepultamento divinos, foram variadamente apreendidas no sentido de que não é um sentimento subjetivo da comoção, da compaixão ou da dor singular humana que

${ }^{33} \mathrm{Id}$.

${ }^{34}$ Moritz Hauptmann (I792-I868) foi um musicólogo e compositor alemão. Há aqui uma diferença em relação à versão do escrito de Dahlhaus contido nos Escritos completos em Io volumes (G. S. Laaber, 2003, v. 5, p. 608), em que ele atribui a expressão "espuma francesa” a Zelter (Carta de C. F. Zelter a J. W. von Goethe, is de abril de I827. In: Briefwechsel zwischen Goethe und Zelter in den Jahren I799-I832. Edição de Munique, v. 20/2), p. 992. Nota da tradução. 
se expressa sobre este acontecimento, e sim é, por assim dizer, a coisa mesma que move, isto é, a profundidade de seu significado por meio da harmonia e seu decurso melódico. ${ }^{35}$

O ouvinte não deve, portanto,

intuir a dor da crucificação, a deposição, não deve formar uma representação universal disso, e sim em seu mais interior si-mesmo [Selbst] ele deve vivenciar [durchleben] o mais interior desta morte e desta dor divina, mergulhar nisso com todo o ânimo, de modo que a coisa se torne algo percebido nele mesmo, que apaga todo o resto e preenche o sujeito apenas com este um elemento. ${ }^{36}$

A unidade da substância espiritual e religiosa na Forma sonora, que Hegel acreditou assim ter descoberto em algumas obras da música sacra antiga, como interpretação estético-histórico-filosófica, lembra involuntariamente a representação de um passado encarnado dos deuses nas antigas estátuas: lembra uma ideia, portanto, para a qual Hegel cunhou o termo "religião da arte" na Fenomenologia do espirito. ${ }^{37}$ Assim, sem que seja necessário deixar-se envolver em argumentações complicadas sobre a estrutura da sistemática hegeliana, parece que, no âmbito da música, a música sacra antiga significou uma espécie de culminação "clássica" entre, de um lado, a fase anterior de desenvolvimento do "simbólico" e, de outro, a mais tardia do "romântico" - assim como no todo do desenvolvimento da arte, a escultura antiga enquanto epítome do "clássico". Em outras palavras: o esquema da história mundial da arte é replicado em menores proporçôes no interior da música - como uma arte no todo romântica, pertencente ao terceiro período.

É evidente que, sob a condição de uma "arte romântica" no todo (que como tal foi a arte de uma era cristã), a identidade "clássica" da substância religiosa

35 Trecho traduzido retirado de HEGEL, G. W. F. Cursos de estética, Tradução de Marco Aurélio Werle e Oliver Tolle. São Paulo, Edusp, 20I4, v. III, p. 320. Nota da tradução. (Ästhetik, 1976, v. 2, p. 304).

${ }^{36}$ Id. Nota da tradução.

37 HEGEL, G. F. W. Phänomenologie des Geistes. Nova edição de H.-F. Wessels e H. Clairmont. Hamburg, 1988, pp. 458 a 488. 
e da Forma intuitiva deve assumir uma forma e significado outros do que na Antiguidade; e pode-se assinalar a mudança, para formular, como deslocamento do objetivo no subjetivo. No entanto, é algo decisivo que o fato tenha tido efeito na estrutura da estética musical, que a filosofia da história da arte de Hegel, assim como a filosofia da história da arte em geral, tenha sido em última instância inspirada religiosa e filosoficamente. E, com respeito à combinação da história da arte e da religião, a sentença proferida por Zelter acerca da Paixão segundo são Mateus, de tão tacanha que ela parecia no início, parece tomar um novo rumo filosófico. Entretanto, a interpretação, para atingir o alvo, deve fazer um aparente desvio, na esteira do qual Hegel e E.T.A. Hoffmann são mais uma vez confrontados.

O escrito de Hoffmann sobre "A música sacra antiga e moderna" ${ }^{8}$ do ano de I8I4, que Hegel sem dúvida conhecia, parte de um problema árduo que determina a estrutura do texto, mas que torna também mais difícil sua compreensão: nomeadamente, a discrepância de Hoffmann, de um lado, elogiar a música sacra de Palestrina a Bach como a irrepetível realização da substância religiosa na música, perdida para o presente, e, de outro, em contrapartida ter visto na música instrumental de Beethoven um progresso musical que não se limitou ao momento técnico-formal, mas antes reivindicou uma significação metafísica. Ao final do escrito, Hoffmann, mesmo que de uma forma vaga, deixa também em aberto a possibilidade de uma restituição da substância autenticamente religiosa a partir do espírito de uma música instrumental interpretada metafisicamente.

Se referirmos agora a sentença que Zelter proferiu como uma declaração hegeliana acerca da Paixão segundo são Mateus ao problema esboçado por Hoffmann, então ele está dizendo nada menos que enfim Hegel, ao final de sua vida, após a conclusão da Estética, ainda considerou a possibilidade da substância religiosa não estar compreendida exclusivamente na música sacra antiga, cuja obra protestante mais importante seria para ele desapontadora enquanto experiência musical, mas antes poderia ser restituída sob as premissas da música instrumental beethoveniana, de cuja interpretação metafísica Hegel já havia suspeitado através de Hoffmann.

${ }^{38}$ HOFFMANN, E.T.A. "Alte und neue Kirchenmusik”. In: Id. Schriften zur Musik. Suplemento. Edição de F. Schnapp. Munique, 1963, pp. 209 a 235 (primeira edição: Allgemeine musikalische Zeitung I6 (I8I4), mais tarde 577 a 584, 593 a 603 e 6II a 6I9). 
A tentativa de interpretação, cujo fundamento filológico é inegavelmente frágil ao extremo, pertence sem dúvida àqueles que quase automaticamente atraem para si mesmos a acusação de "interpretar demasiadamente": uma acusação, que deveria ser suportada, entretanto, por todo aquele que luta para sair do lugar ao invés de meramente parafrasear textos e, com suas próprias e mais fracas palavras, orbitar o assunto. 